THE aim of the present study was to investigate the in terrelationship of the kin in system, nitric oxide and eicosanoids in the acute phase of antigen-induced arth ritis (AIA) in rabbits. The arth ritis $w$ as induced in immunized rabbits and the following parameters were evaluated 24 hours later: leukocyte influx (total and differential white cell count), vascular permeability (Evans's blue method), and synovial PMN cell in filtrate. $\mathrm{PGE}_{2}$ and $\mathrm{LTB}_{4}$ (radioim munoassay) levels were quantified in the synovial fluid. The animals were pre-treated with $20 \mathrm{mg} / \mathrm{kg} /$ day during 14 days with L-NAME or D-NAME and/or Enalapril $(0.12 \mathrm{mg} /$ $\mathrm{kg} / \mathrm{day}-14$ days), and/or the $\mathrm{B} 2$ antagon ist of Bradykinin HOE $140(0.9 \mathrm{mg} / \mathrm{kg})$. Our results showed that L-NAME was effective in the prevention of AIA with reduction of all inflammatory parameters analyzed. Enalapril partially reverted the L-NAME anti-inflammatory effects. The simultaneous treatment with HOE 140 abolished this reversion and returned the in flam matory parameters to the levels observed in L-NAME treated animals. Our results suggest that pressoric alterations induced by L-NAME could not account for all its anti-inflammatory action in this model of ex perimental arthritis. Additionally the contribution of the kinin system in AIA was characterized as well as its in teraction $w$ ith eicosanoids and nitric oxide.

Key words: Experimental arthritis, Nitric oxide, Eicosanoids, Bradykinin

\section{Interrelationship of the kinin system, nitric oxide and eicosanoids in the antigen-induced arthritis in rabbits}

\author{
Fernando Alfonso Salamea Palácios ${ }^{1}$, \\ Gilberto Santos Novaes' ${ }^{2}$ Maria Luiza Guzzo', \\ leda Maria Magalhães Laurindo ${ }^{1}$ and \\ Suzana Beatriz Verissimo de Mello ${ }^{1, C A}$
}

${ }^{1}$ Rheumatology Division, School of Medicine, University of São Paulo, Av. Dr. Arnaldo, 455, São Paulo, CEP - 0124-6903, SP, Brazil, and

${ }^{2}$ Rheumatology Division, Department of Medicine, Catholic University of São Paulo., Sorocaba, SP, Brazil

${ }^{\mathrm{CA}}$ Corresponding Author

Tel: $55-011-30667200$

Fax: 55-011-2801834

Email: reumato@edu.usp.br

\section{Introduction}

Rheumatoid arthritis is an autoimmune disease in which chronic inflammation of the synovial lining cells produce pain, swelling and progressive erosion of the synovial joints. Dumonde \& Glynn ${ }^{1}$ first described antigen-induced arthritis (AIA) in rabbits. AIA evolves as a progressive immunological arthritis, which in histopathological terms closely resembles rheumatoid arthritis in man. The acute phase of AIA is a typical Arthus reaction which occurs in the joint with complement activation and polymorphonuclear (PMN) leukocyte migration. ${ }^{2}$

Nitric oxide (NO) is a very small and ubiquitous molecule synthesized from L-arginine by nitric oxide synthases (NOS). NO is produced in the joint by chondrocytes, ${ }^{3-6}$ synoviocytes ${ }^{6,7}$ and osteoblasts. ${ }^{6}$ It has been involved in inflammatory reactions with both pro and anti-inflammatory properties. Endogenous release of $\mathrm{NO}$ could act as anti-inflammatory through the reduction of leukocyte adhesion, ${ }^{8,9}$ and inhibition of synthesis of cyclo-oxygenase products such as prostaglandin $\mathrm{E}_{2}\left(\mathrm{PGE}_{2}\right)$, thromboxane $\mathrm{B}_{2}$ $\left(\mathrm{Tx}_{2}\right)$ and interleukin-6 (IL-6). ${ }^{10}$ Endogenous NO has also been described as a pro-inflammatory molecule showing interactions with cytokines ${ }^{11-13}$ and inflammatory products of the cyclo-oxygenase pathway. ${ }^{14-20}$ Studies have shown that NO increases inte rleukin-1 $\beta$ (IL-1) and eicosanoid products which may result in the exacerbation of the inflammatory response. ${ }^{12,13}$ The participation of $\mathrm{NO}$ in intraarticular inflammatory process has been fully described in arthritic patients. ${ }^{21,22}$ NOS inhibitors have been widely used in studies of NO influence in the inflammatory process. The administration of NOS inhibitors in the experimental arthritis in rats was followed by reduction in the intra-artic ular accumulation of leukocytes, joint erosion, and paw swelling as well as histopathological abnormalities..$^{23-27}$ Inhibition of NO biosynthesis by L-arginine antagonism reduced $\mathrm{PGE}_{2}$ production by condrocytes ${ }^{3}$ without effect upon the increased production of $\mathrm{PGE}_{2}$ by synoviocytes stimulated with IL-1. ${ }^{7}$ Moreover, endogenous release of $\mathrm{NO}$ enhances macrophage cyclooxygenase (COX) activity and increases the production of pro-inflammatory prostaglandins. ${ }^{13,28}$ Several studies suggest that $\mathrm{NO}$ participates in the inflammatory response and joint destruction. Slices of rabbit 
articular cartilage synthesized large quantities of NO following stimulation with human recombinant IL-1 $\beta$. Treatment of cartilage fragments with NOS inhibitor decreased NO synthesis stimulated by IL-1 $\beta$ and restored proteoglycan synthesis. ${ }^{29}$ We previously verified that chronic treatment of arthritic rabbits with L-NAME evoked reduction of the cellular influx and protein leakage to the articular cavity. Additionally the synovial fluid of these animals showed reduction of $\mathrm{PGE}_{2}$, IL1 and $\mathrm{NO}_{2} / \mathrm{NO}_{3}$ levels. ${ }^{30}$ Chronic adminis tration of NOS inhibitors causes vasoconstriction with potential reduction in cell migration. The contribution of this pressoric alteration evoked by chronic treatment with L-NAME to its anti-inflammatory action as well as the possible links between NO and other mediators of inflammatory reaction have so far been poorly studied in the articular environment. Thus, in the present study we analyzed the leukocyte migration, protein leakage, synovium polymorphonuclear cell infiltrate and eicosanoids production in the synovial fluid of knee joints of rabbits with AIA treated with NOS inhibitor, Enalapril and the B2 antago nist of Bradykinin HOE 140.

\section{Material and methods}

\section{Induction of arthritis}

The Animal Ethics Committee of COBEA (Brazilian College of Experimental Animals) has approved all experimental procedures performed on animals in accordance with procedures set by UFAW (The Universities Federation for Animals Welfare). Male New Zealand White rabbits were sensitized with $5 \mathrm{mg}$ of methylated bovine serum albumin (mBSA Sigma) in $1 \mathrm{ml}$ Fre und's complete adjuvant (Gibco) and $1 \mathrm{ml}$ of sterile saline through injections at subcutaneous and muscular sites in the suprascapular and gluteal regions, respectively. Seven days after the immunization the animal was once a week boosted with intradermical injection of $1 \mathrm{mg} / \mathrm{ml}$ of mBSA. Then, cutane ous Arthus reaction characterized by central necrosis was observed 24 h later. Simultaneously, the serum antibody titles against mBSA were quantified by immunodiffusion. The animals used in the experiment were those who appropriately responded to the second cutaneous challenge and have had anti-mBSA titles over $1 / 8$. Seven days after the third booster, arthritis was induced in the knee joint by the injection of $0.5 \mathrm{ml}$ of a sterile solution of $\mathrm{mBSA}(2 \mathrm{mg} / \mathrm{ml})$ into the articular cavity. The contralate ral joint was injected with saline. Twenty four hours after intra-articular challenge the animal was anaesthetized with a mixture of xylazine $(5 \mathrm{mg} / \mathrm{kg})$ associated with ketamine $(50 \mathrm{mg} / \mathrm{kg})$ by intramuscular injection and after that it was killed by intrave nous injection of $2.0 \mathrm{ml}$ of KCI $20 \%$

\section{Treatments}

A group of animals was randomly treated with L-NAME (Sigma), a competitive NOS inhibitor, or its inactive form D-NAME (Sigma). The dose for both tre atments was of $20 \mathrm{mg} / \mathrm{kg} /$ day mixed with drinking water. Drugs were administered for 2 weeks prior to the induction of arthritis, and started simultane ously with the second booster. Another group of animals was randomly treated with Enalapril, an angiotensin converting enzyme (ACE), which produces blood pressure decrease. The treatment with Enalapril started simultaneously with L-NAME and the dose of the drug was $0.12 \mathrm{mg} / \mathrm{kg} /$ day mixed with drinking water. The B2 antagonist of Bradykinin HOE 140 (D-Arg-[Hyp $\left.{ }^{3}, \mathrm{Thl}^{5}, \mathrm{Dtic}^{5}, \mathrm{Oic}^{8}\right]$-bradykinin) was injected subcutaneously in a dose of $0.3 \mathrm{mg} / \mathrm{kg}$ every 8 hours after the arthritis induction.

\section{Sampling of synovial fluid}

Immediately after the sacrifice $2 \mathrm{ml}$ of saline containing EDTA $(1 \mathrm{mg} / \mathrm{ml})$ was injected into the knee joint. Synovial fluid was aspirate $d$, the joint was opened and the remainder of the synovial fluid as well as synovial membrane was recovered. Total and differential leukocyte count was done in a Neubauer chamber under light microscopy. For the differential white cell count smears were prepared from a cell pellet and stained with Giemsa. The synovial fluid was stored at $-70^{\circ} \mathrm{C}$ for eicosanoids determination.

\section{Assessment of vascular permeability response with Evans's blue dye}

Before mBSA injection to induce arthritis the animals received iv. $20 \mathrm{mg} / \mathrm{kg}$ of Evans's blue dye in a $2.5 \%$ saline solution. The dye combines with the proteins of the plasma giving rise to a tagged macromolecule that passes the endothelial barrier only to a negligible extent under normal conditions, but it is deposited in the tissues under circumstances of increased vascular permeability. The synovial fluid was centrifuged and the optical density colorimetrically assessed at $630 \mathrm{~nm}$. The concentration of dye bound to prote in in the synovial fluid was estimated from a standard graph recording the optical density of serial dilution of a know n sample of Evans's blue in $\mathrm{NaCl}$. Results are expressed as $\mu \mathrm{g}$ of protein $/ \mathrm{ml}$ of synovial fluid.

\section{Synovial membrane histology}

After sampling the synovial fluid and opening the articular cavity, the synovial membrane was excised and sections were stained with hematoxylin and eosin for evaluation of PMN cell infiltrate under light microscopy. The synovium PMN cell infiltrate was quantified as absent or rare, mild, or severe by an observer blinded to the experimental groups. 


\section{Assay of eicosanoids}

$\mathrm{PGE}_{2}$ and $\mathrm{LTB}_{4}$ levels were assayed in the synovial fluid using commercial kits (Amersham, UK) as previously described. ${ }^{31,32}$ The radioimmunoassays were performed in polypropylene tubes with the reagents diluted in phosphate-buffered saline with gelatin and thimerosal. One hundred microliters each of unknow n samples, tracers $\left(\mathrm{I}^{125} \mathrm{PGE}_{2}\right.$ or $\left.\mathrm{H}^{3} \mathrm{LTB}_{4}\right)$, and rabbit antiserum to each eicosanoid were combined and incubated overnight at $8^{\circ} \mathrm{C}$ for $\mathrm{LTB}_{4}$ determination and incubated for 2 hours at $25^{\circ} \mathrm{C}$ in a water bath for $\mathrm{PGE}_{2}$ determination. Unbound radiolabeled $\mathrm{PGE}_{2}$ was removed by the addition of $250 \mu \mathrm{l}$ of donkey anti-rabbit serum coated onto magne tizable polymer particles, and $\mathrm{LTB}_{4}$ by the addition of $250 \mu \mathrm{l}$ of $2 \%$ charcoal suspension coated with $0.4 \%$ dex tran to the tubes. After centrifugation the residual bound activity was measured in each tube by counting $\mathrm{I}^{125}$ $\mathrm{PGE}_{2}$ in a gamma scintillation counte $r$ and $\mathrm{H}^{3} \mathrm{LTB}_{4}$ in a beta scintillation counter. Cross reactivities of the antiserum with other eicosanoids were below $0.05 \%$ The assay sensitivities were 1.25 to $160 \mathrm{pg} /$ tube $\left(\mathrm{PGE}_{2}\right)$, and 1.6 to $200 \mathrm{pg} /$ tube $\left(\mathrm{LTB}_{4}\right)$.

\section{Statistics}

Results are expressed as mean \pm s.e.m. The results were analyzed by Student's $t$ test or by repeated measured ANOVA and compared with student New man Keuls test. The chosen level of signific ance was 0.05 .

\section{Results}

\section{Leukocyte influx and vascular permeability in the synovial fluid}

To investigate the contribution of pressoric alte ration to the anti-inflammatory properties of chronic L-NAME treatment, leukocyte influx and protein leakage to the articular cavity was quantified in the synovial fluid collected from animals treated with L-NAME or D-NAME with or without Enalap ril. Synovial fluid cells and vascular permeability were measured 24 hours after articular challenge with mBSA. Panel A (Fig. 1) show s the effect of L-NAME compared with control animals in the reduction of cellular migration to the inflamed area. The reduced migration occurs mainly in the number of polymorphonuclear (PMN) leukocytes, the central cell in the acute phase of the inflammatory reaction, although mononuclear $(\mathrm{MN})$ cell migration was also affected. The simultaneous administration of Enalap ril with L-NAME partially restores this parameter. The cellular influx to the articular cavity observed in animals treated with Enalapril alone was similar to that observed in the animals treated with L-NAME plus Enalapril. The synovial fluid of the control joint, injected $w$ ith saline exhibited only resident cells (dotted line). Leukocyte counts in the articular cavity of D-NAME treated animals did not differ from the leukocyte count in control animals, which drank only water ${ }^{30}$.

The vascular permeability show $\mathrm{n}$ in panel $\mathrm{B}$ was quantified by Evans's blue method. Our results showed a significant decrease in protein leakage to the artic ular cavity in the synovial fluid collected from L-NAME treated animals. The knee joint injected w ith saline showed low levels of dye bound to protein. Similar findings in the protein leakage to the articular cavity were observed in both D-NAME tre ated animals and those which drank only water. The protein leakage analyzed in the joint fluid of animals treated with Enalap ril or Enalap ril plus L-NAME did not differ from the control animals. In all groups evaluated the synovial membrane PMN cell infiltrate showed a similar pattern to the PMN infiltrate observed in the synovial fluid (data not shown). In a previous paper we showed that the synovial membrane of animals receiving mBSA intra-artic ularly had inte nse PMN cell infiltrate at 24 hours. Treatment with the NOS inhibitor L-NAME, prior to the induction of arthritis, greatly reduced the cell infiltration in the synovial membrane 24 hours afte $r$ the induction of arthritis. ${ }^{30}$ Fig. 2, Panels A and B, shows the inflammatory parameters analyzed in animals simultaneously treated with the B2 antagonist of Bradykinin HOE 140. The cellular influx and the protein leakage analyzed in the synovial fluid of these animals were remarkably reduced when compared with the same parameters observed in animals without HOE 140 treatment. It is worth noting that the $\mathrm{HOE}$ treatment drastically reduced the inflammatory parameters measured in the synovial fluid of L-NAME plus Enalapril treated animals. These results show the importance of the kinin system in the development of AIA in rabbits.

\section{Eicosanoids levels in the synovial fluid}

The synovial fluid of animals treated with L-NAME, D-NAME, Enalapril and HOE140 was collected, and the eicosanoids $\mathrm{PGE}_{2}$ and $\mathrm{LTB}_{4}$ assayed by radioimmunoassay. The results are show $\mathrm{n}$ in Figs 3 and 4 respectively. The $\mathrm{PGE}_{2}$ level $\mathrm{w}$ as signific antly reduced with L-NAME treatment, in accordance with our previous results. ${ }^{30}$ The simultaneous treatment with Enalapril completely reverted this inhibition. The treatment of animals with HOE 140 drastically reduced the level of $\mathrm{PGE}_{2}$ in all groups evaluated. It is important to note that the same result even occurred in the group of animals treated only with Enalapril plus HOE 140 . The level of $\mathrm{LTB}_{4}$ show $\mathrm{n}$ in Fig. 4 exhibited a quite different pattern of alteration. Although reduced after treatment with L-NAME alone or combined with Enalapril, the level of $\mathrm{LTB}_{4}$ was reverted to that observed in control animals when the tre atment included HOE 140. Treatment w ith D-NAME did not affect the synovial fluid levels of eicosanoids 
when compared with the results obtained in animals which drank only water. ${ }^{30}$

\section{Discussion}

Our previous results clearly implicate nitric oxide in the IL-1 induced $\mathrm{PGE}_{2}$ production in the synovial fluid of acute arthritis in rabbits. ${ }^{30}$ In this study we also demonstrate that treatment with the NOS inhibitor L-NAME was associated with a reduction in some signs of acute articular inflammation in rabbits such as vascular permeability and synovial membrane PMN cell infiltrate. In the acute phase of AIA we noticed a reduction in the number of leukocytes coming to the inflamed area. This finding is consistent with the study of Belenky et al., ${ }^{33}$ who found that NOS inhibitors atte nuated chemotax is of unstimulated and primed PMN leukocytes. Kaplan et al., ${ }^{34}$ using peripheral human neutrophils incubated with the NOS inhibitor, LNMA, demonstrated a reduction of leukocyte chemotax is to FMLP. This inhibition could be overcome if L-arginine or dibutyryl cGMP were added together with the LNMA. These studies point out the importance of NO in the direction of cell movement. Our results clearly show that under inflammatory challenge the migratory response of PMN cells and the synovium PMN cell infiltrate were reduced in animals treated with L-NAME. This suggests that the endothelial lining of vessels within the rabbit synovium may be an unusual microvascular network. We hypothesized that chronic treatment with an NOS inhibitor promotes vascular pressoric alteration that could be account for its anti-inflammatory action. The simultaneous treatment of these animals with Enalapril, an ACE inhibitor, restored the cellular influx, protein leakage and eicosanoids production almost to the normal range observed in control arthritic joints. $\mathrm{BK}$ induces increase in the blood flow of the rabbit
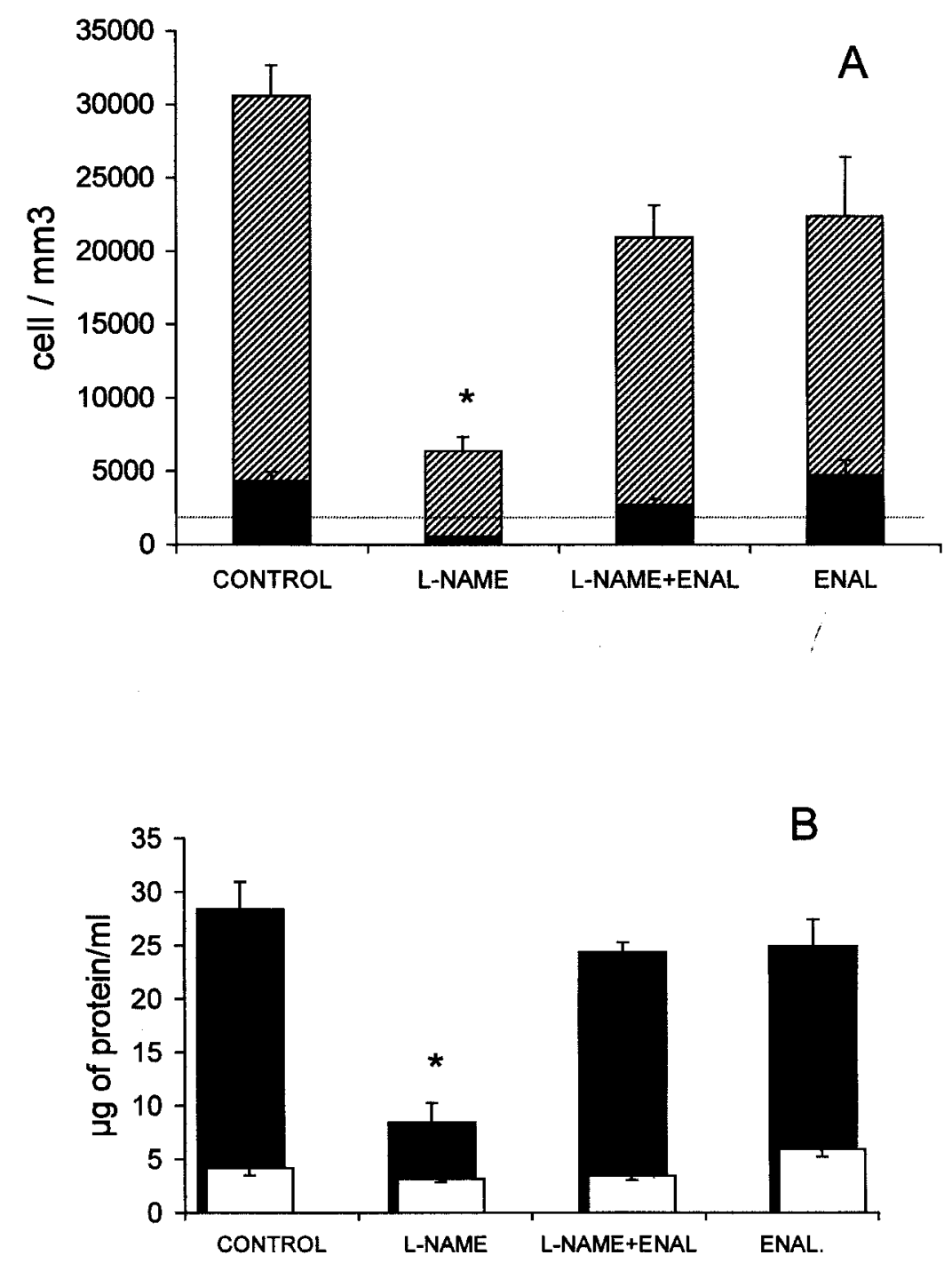

FIG. 1. Panel A: Total and differencial cell counts (polymorphonuclear $=\mathbb{\$}$; mononuclear $=\mathbf{\square}$ ), and Panel $B$ : Vascular permeability (BSA injected joint = black columns; Saline injected = white columns) assessed in the joint fluid of rabbits with 24 hours of antigen-induced arthritis. The animals were treated before induction of arthritis with L-NAME $(n=16)$, Enalapril $(n$ $=11)$, L-NAME+Enalapril $(n=10)$ and compared with control animals $(n=20)$. The results expressed mean \pm s.e.m.* ${ }^{*}<0.05$. 

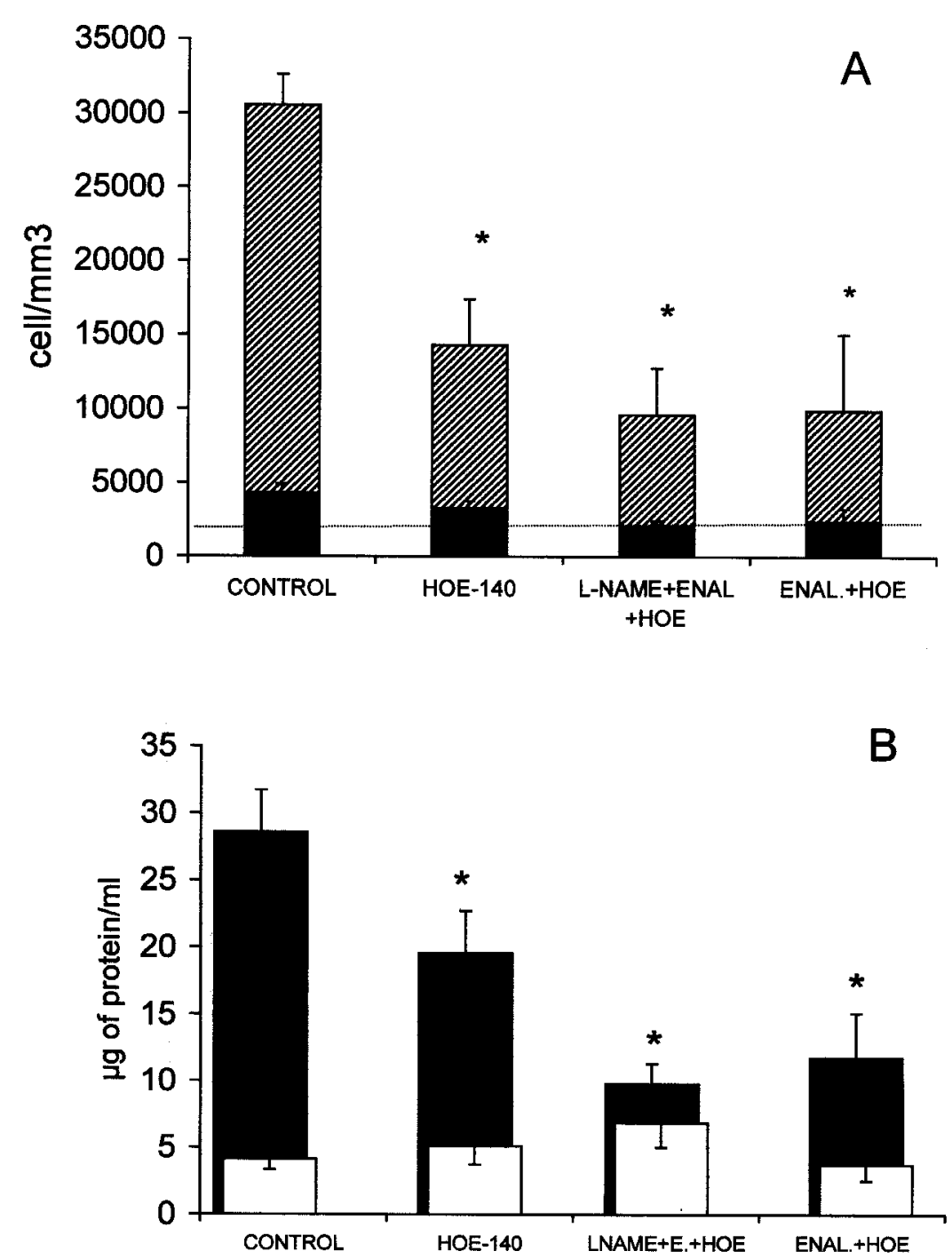

FIG. 2. Panel A: Total and differencial cell counts (polymorphonuclear $=\mathbf{\$}$; mononuclear $=\mathbf{\square}$ ), and Panel $B$ : Vascular permeability (BSA injected joint = black column; Saline injected $=$ white column) assessed in the joint fluid of rabbits with 24 hours of antigen-induced arthritis. The animals were treated before induction of arthritis with HOE $140(n=4)$, Enalapril $+\mathrm{HOE}$ $(n=4)$, L-NAME + Enalapril + HOE $(n=4)$ The results expressed mean \pm s.e.m. ${ }^{*}<0.05$. compared with mean of 20 control animals.

synovium via activation of $\mathrm{B} 2$ receptors. ${ }^{35}$ Then, we also analyzed the participation of the kinin system through co-adminis tration of a B2 antagonist of BK HOE 140 to the animals, before and during the arthritis development. This treatment promoted remarkable reduction of cellular influx, prote in leakage and $\mathrm{PGE}_{2}$ level in the synovial fluid. It is worth noting that concomitant adminis tration of HOE 140 completely abolished the increase of the inflammatory parameters promoted by Enalapril to L-NAME tre ated animals.

NO appears to be generated by the vascular endothelial cells via constitutive NO synthase stimulated by inflammatory mediators like histamine, 5 hydroxytryptamine and Bradykinin or by the inducible enzyme carried to the inflammatory site by PMN cells. ${ }^{36}$ The magnitude in the reduction of the inflammatory parameters observed with HOE 140 treatment suggests that $\mathrm{NO}$ generation in experimental arthritic joints follows BK stimulation of B2 receptors. The results obtained in all animals treated with the B2 antagonist of Bradykinin irrespective of other treatments were similar to the values observed in animals treated only with L-NAME and included the level of $\mathrm{NO}_{2} / \mathrm{NO}_{3}$ (data not shown). The only exception $w$ as in the level of $\mathrm{LTB}_{4}$ measured in the experimental joints of HOE treated animals, which result is compared with those obtained without HOE treatment. This finding suggests a possible inhibitory action of kinin system products in the lipooxygenase pathway.

$\mathrm{LTB}_{4}$ would be considered a potent chemotactic in the acute phase of inflammatory response. ${ }^{37}$ We have recently found that $\mathrm{LTB}_{4}$ levels decreased in the synovial fluid of untreated animals at 24 hours of arthritis when compared with $\mathrm{LTB}_{4}$ levels found in 


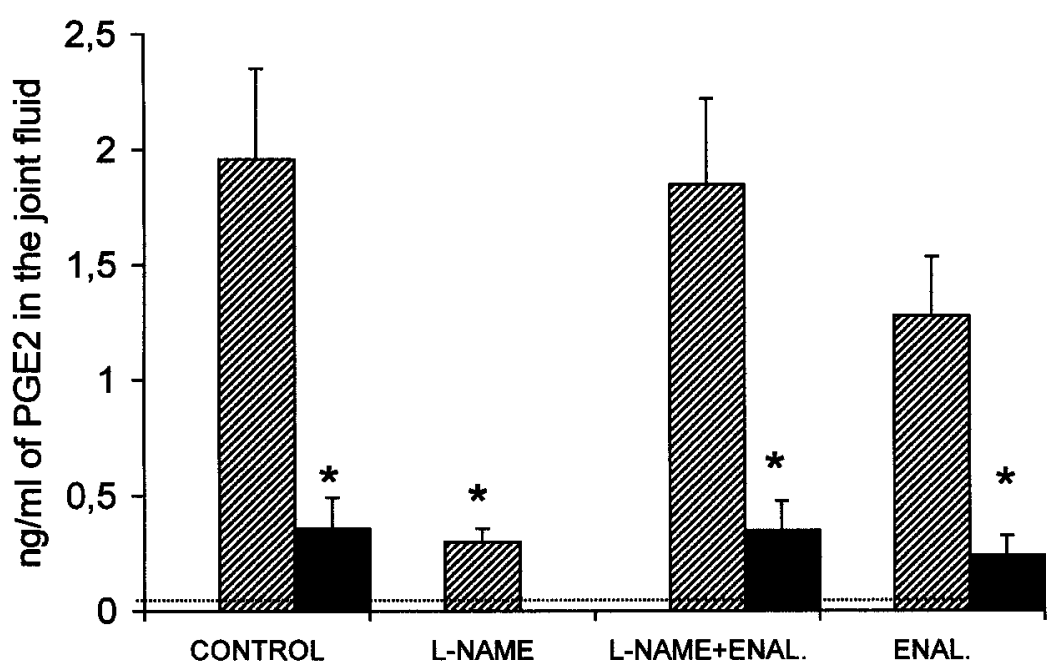

FIG. 3. The striped column shows the $\mathrm{PGE}_{2}$ levels in the synovial fluid of animals treated with Enalapril $(n=7), \mathrm{L}-\mathrm{NAME}+$ Enalapril $(n=7)$ and control animals $(n=10)$. The black column shows means of four animals submitted to the same treatments and simultaneously injected with HOE 140 . The results expressed mean \pm s.e.m. ${ }^{*}<0.05$ compared with groups without $\mathrm{HOE}$ 140 treatment.

animals at 4 hours of arthritis (LTB) 4 th $\mathrm{h}=$ $\left.2.48 \pm 0.16 \mathrm{ng} / \mathrm{ml} ; \mathrm{LTB}_{4} 24 \mathrm{th} \mathrm{h}=0.95 \pm 0.14 \mathrm{ng} / \mathrm{ml}\right) .^{38}$ The reduced levels of $\mathrm{LTB}_{4}$ in animals treated only with Enalap ril corroborate previous results in arth ritic patients treated for arterial hypertension with ACE inhibitors. ${ }^{39,40}$ The reduced levels of $\mathrm{LTB}_{4}$ and the impaired migration of leukocytes to the articular cavity in L-NAME treated animals suggest that another mediator apart, $\mathrm{LTB}_{4}$ possibly can be involved in the cell attraction to the articular cavity in this phase of AIA development.

The inte ractions between PGE 2 IL-1 and NO synthesis have been related in many studies. $3,4,5,12,20,41$ These studies show that the endogenous release of $\mathrm{NO}$ enhances COX activity with further increase of $\mathrm{PGE}_{2}$. High concentrations of $\mathrm{PGE}_{2}$ inhibited NOS expression and decreased NO synthesis. ${ }^{14}$ When NO production was blocked by NOS inhibitors both NO and $\mathrm{PGE}_{2}$ simultaneously decreased. ${ }^{12,16-19,25,28,42}$ NOS inhibitors also block cytokine induced release of PGE. ${ }^{11,13}$ In these in vitro experiments $\mathrm{NO}$ seems to be one of the most important signals in the activation of cyclo-oxygenase to produce $\mathrm{PGE}_{2}$. We previously found that inhibition of NO production with L-arginine antagonist L-NAME significantly reduced IL-1 $\beta$ and $\mathrm{PGE}_{2}$ levels in the synovial fluid, with simultaneous reduction of total $\mathrm{NO}_{2} / \mathrm{NO}_{3}$ and suppression of AIA. ${ }^{30}$ In this study we verified that treatment with an ACE inhibitor, Enalapril, was efficient in the reversion of inflammatory parameters in the synovial fluid induced by NOS inhibition. This effect may not be in consequence of arterial pressure normalization but due to Bradykinin accumulation at the site of injury and was completely blocked by administration of $\mathrm{BK}$ antagonist HOE 140.

Together our results show that the pressoric mechanism acting in chronic administration of L-NAME did not account for all anti-inflammatory properties of NOS inhibitors in the development of

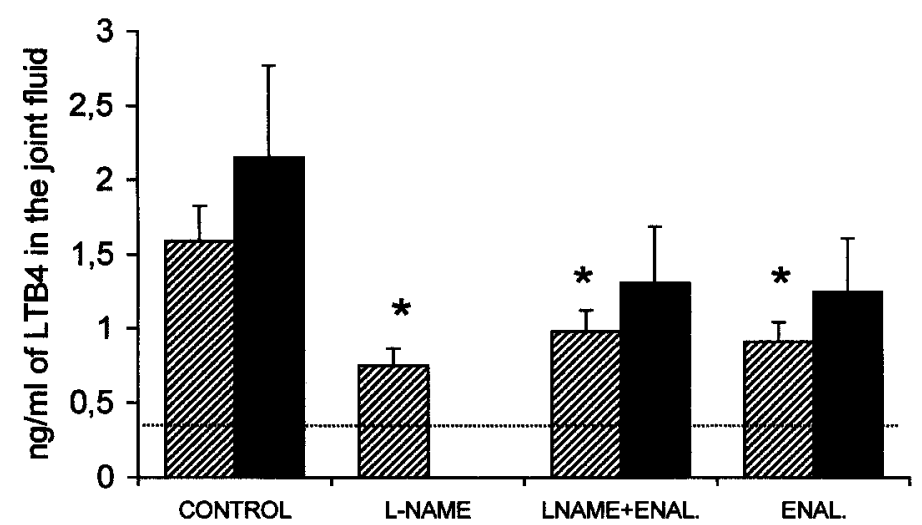

FIG. 4. The striped column shows the $\mathrm{LTB}_{4}$ levels in the synovial fluid of animals treated with Enalapril $(n=7)$, L-NAME + Enalapril $(n=7)$ and control animals $(n=10)$. The black column shows means of four animals submitted to the same treatment and simultaneously injected with HOE 140 . The results expressed mean \pm s.e.m. ${ }^{*}<0.05$ compared with control animals. 
AIA in rabbits. Additionally we demonstrate the participation of Bradykinin in the acute phase of antigen-induced arthritis in rabbits as well as the interrelationship of the kinin system with $\mathrm{NO}$ and eicosanoids production in the arthritic joint.

ACKNOWLEDGEMENTS. Supported by Fundação de Amparo à Pesquisa do Estado de São Paulo (FAPESP) and Fundos Remanescentes of Brazilian Society of Rhe umatology.

We wish to thank Ms Maria de Fatima de Almeida for technical assistance and Dr Gilberto de Nucci for constructive discussion. We wish to thank Hoechst for HOE 140 supply.

\section{References}

1. Dumonde DC, Glynn LE. The production of arthritis in rabbits by an immunological reaction to fibrin. Br J Exp Pathol 1962; 43: 373-383.

2. De Shazo CV, Henson PM, Cochrane CG. Immunologic arthritis in rabbits. J Clin Invest 1972; 51: 50-57.

3. Stadler J, Stefanovic-Racic M, Billiar TR, Curran RD, McIntyre LA, Georgescu HI, Simmons RL, Evans CH. Articular condrocytes synthesize nitric oxide in response to cytokines and lipopolysaccharide. J Im munol 1991; 147: 3915-3920.

4. Palmer RM, Hickery MS, Charles IG, Moncada S, Bayliss MT. Induction of nitric oxide synthase in human condrocytes. Biochem Biophys Res Commun 1993; 193: 398-405.

5. Stefanovic-Racic M, Stadler J, Georgescu HI, Evans CH. Nitric ox ide and energy production in articular chondrocytes. J Cell Physiol 1994; 159: 274-280.

6. Grabowski PS, Macpherson H, Ralston SH. Nitric oxide production in cells derived from the human joint. Br J Rheumatol 1996; 35: 207-212.

7. Stefanovic-Racic M, Stadler J, Georgescu HI, Evans CH. Nitric oxide synthesis and its regulation by rabbit synoviocytes. J Rheumatol 1994 21(10): 1892-1898.

8. Kubes P, Suzuki M, Granger DN. Nitric Oxide. An endogenous modulator of leukocyte adhesion. Proc Natl Acad Sci USA 1991; 88: 4651-4655.

9. Gaboury J, Woodman RC, Grange r DN, Reinhardt P, Kubes P. Nitric oxide prevents leukocyte adherence: role of superoxide. Am J Physiol 1993; 265: 862-867.

10. Stadler J, Harbrecht BG, Di Silvio M, Curran RD, Jordan ML, Simmons RL, Billiar TR. Endogenous nitric oxide inhibits the synthesis of cyclooxygenase products and interleukin-6 by rat Kupffer cells. J Leuk Biol 1993 53: $165-172$.

11. Kelner MJ, Uglik SF. Mechanism of prostaglandin $E_{2}$ rele ase and increase in $\mathrm{PGH}_{2} / \mathrm{PGE}_{2}$ is ome rase activity by PDGF: involve ment of nitric oxide. Arch Biochem Biophys 1994; 312: 240-243.

12. Inoue T, Fukuo K, Morimoto S, Koh E, Ogihara T. Nitric oxides mediates interleukin-1-induced prostaglandin $\mathrm{E}_{2}$ production by vascular smooth muscle cells. Biochem Biophys Res Commun 1993; 194: 420-424.

13. Corbett JA, Kwon G, Turk J, McDaniel ML. IL-1 beta induces the coexpression of both nitric oxide synthase and cyclooxygenase by islets of Langerhans: activation of cyclooxygenase by nitric oxide. Biochem 1993; 32: 13767-13770.

14. Milano S, Arcoleo F, Dieli M, D’Agostino R, D'Agostino P, De Nucci G, Cillari E. Prostaglandin $\mathrm{E}_{2}$ regulates inducible nitric oxide synthase in the murine macrophage cell line J774. Prostaglandins 1995; 49: 105-115.

15. Molina HF, Lledo A, Guaza C. Evidence for cyclooxygenase activation by nitric oxide in astrocytes. Glia 1995; 15: 167-172.

16. Davidge ST, Baker PN, Laughlin MK, Roberts JM. Nitric oxide produced by endothelial cells increases production of eicosanoids through activation of prostaglandin H synthase. Circ Res 1995; 77: 274-283.

17. Salve mini D, Seibert K, Masferrer JL, Misko TP, Currie MG, Needle man P. Endogenous nitric oxide enhances prostaglandin production in a model of renal inflammation. J Clin Invest 1994; 93: 1940-1947.

18. Salve mini D, Settle SL, Masferrer JL, Seibert K, Currie MG, Needle man P. Regulation of prostaglandin production by nitric oxide; an in vivo analys is. Br J Pharma col 1995; 114: 1171-1178.

19. Sw ierkosz TA, Mitchell JA, Warner TD, Botting RM, Vane JR. Co-induction of nitric oxide synthase and cyclooxygenase: interactions between nitric oxide and prostanoids. Br J Pharmacol 1995; 114: 1335-1342.

20. Tetsuka T, Dafhna-Iken D, Srivas tava SK, Baier LD, DuMaine J, Morrisson AR. Cross-talk between cyclooxygenase and nitric oxide pathways: prostaglandin $\mathrm{E}_{2}$ negatively modulates induction of nitric oxide synthase by interleukin 1. Proc Natl Acad Sci USA 1994; 91: 12168-12172.

21. St Clair EW, Wilkinson WE, Lang T, Sanders L, Misukonis MA, Gilke son GS, Pisetsky DS, Granger DL, We inberg JB. Increased expression of blood mononuclear cell nitric oxide synthase type 2 in Rheumatoid Arthritis patients. J Exp Med 1996; 184: 1173-1178.

22. Novaes GS, Mello SBV, Laurindo IMM, Palacios FAS, Cossermelli W. Intraarticular nitric oxide levels in patients with rheumatoid arthritis. Ver Hosp Clin Fac Med S. Paulo 1997; 52(2): 55-59.

23. Mc Cartney-Francis N, Allen JB, Mizel DE, Abina JE, Xie QW, Nathan CF, Wahl SM. Suppression of arthritis by an inhibitor of nitric oxide synthase. J Exp Med 1993; 178: 749-754.

24. Stefanovic-Racic M, Meyers K, Meschter C, Coffey JW, Hoffman RA, Evans CH. N-Monomethyl arginine, an inhibitor of nitric oxide synthase, suppresses the development of adjuvant arthritis in rats. Arthritis Rheum 1994; 37: 1062-1069.

25. Ianaro A, O'Donnel CA, Di Rosa M, Liew FY. A nitric oxide synthase inhibitors reduces inflammation, down-regulates inflammatory cytokines and enhances interleukin-10 production in carrage enin-induced edema in mice. Im munol 1994; 82(3): 370-375.

26. Stefanovic-Racic M, Meyers K, Meschter C, Coffey JW, Hoffman RA, Evans CH. Comparison of the nitric oxide synthase inhibitors methylarginine and aminoguanidine as prophylactic and therape utic agents in rat adjuvant arthritis. J Rheumatol 1995; 22: 1922-1928.

27. Weinberg JB, Granger DL, Pisetsky DS, Seldin MF, Misukonis MA, Mason SN, Pippen AM, Ruiz P, Wood ER, Gilkeson GS. The role of nitric oxide in the pathogenesis of spontaneous murine autoimmune disease: increased nitric oxide production and nitric oxide synthase expression in MRL-tpr/ lpr mice, and reduction of spontaneous glomerulonephritis and arthritis by orally administered NG-monomethyl-L-arginine. J Exp Med 1994; 179: $651-660$

28. Salve mini D, Misko TP, Masferrer JL, Seibert K, Currie MG, Needle man P. Nitric oxide activates cyclooxygenase enzymes. Proc Natl Acad Sci USA 1993; 90: 7240-7244.

29. Taskiran D, Stefanovic-Racic M, Georgescu H, Evans CH. Nitric oxide mediates suppression of cartilage proteoglycan synthesis by interleukin1. Biochem Biophys Res Commun 1994; 200: 142-148.

30. Mello SBV, Novaes GS, Laurindo IMM, Maciel FMB, Cossermelli W. NOs inhibitor influences prostaglandin and Interleukin 1 production in experimental arthritic joint. Inflamm Res 1997; 46: 72-77.

31. Salmon JA. A radioimmunoassay for 6-Keto-prostaglandin F1 alfa. Prostaglandins 1978; 15: 383-397.

32. Salmon JA, Simmons PM, Palmer RMJ. A radioimmunoassay for leukotriene $\mathrm{B}_{4}$. Prostaglandins 1982; 24: 225-235.

33. Belenky SN, Robbins RA, Rennard SI, Gossman GL, Nelson KJ, Rubinstein I. Inhibitors of nitric oxide synthase attenuate human neutrophil che motax is in vitro. J Lab Clin Med 1993; 122: 388-394.

34. Kaplan SS, Billiar T, Curran RD, Zdziarski UE, Simmons RL, Basford RE. Inhibition of neutrophil chemotax is with $\mathrm{Ng}$-monomethyl-L-arginine: a role for cyclic GMP. Blood 1989; 74: 1885-1887.

35. Cambridge H, Brain SD. Kinin B2 and B1 receptor-mediated vasoactive effects in rabbit synovium. Peptides 1998; 19: 569-576.

36. Radomsky MW, Palmer RM, Moncada S. Glucocorticoids inhibit the expression of na inducible, but not the constitutive nitric oxide synthase in vascular endothelial cells. Proc Natl Acad Sci USA. 1990; 87: 10043-10047.

37. Samuelsson B, Dahlen SE, Lindgren JA, Rouzer CA, Serhan CN. Leukotrienes and lipoxins: structures, biosynthesis, and biological effects. Science 1987; 237: 1171-1176.

38. Novaes GS, Mello SBV, Laurindo IMM, Cossermelli W. Low-dose methotrexate decreases intraarticular prostaglandin and interleukin-1 levels in antigen-induced arthritis in rabbits. JRheum atol 1996; 23(12): 2092-2097.

39. Martin MFR, Mckenna F, Bird HA, Surral KE, Dix on JS, Wright V. Captopril a new treatment for rheumatoid arthritis? Lancet 1984: 1325-1328.

40. Bird HA, Le Gallez PI, Dix on JS, Catalano MAA, Traficante A, Liauw LA, Sussman H, Rotman H, Wright V.A Clinical and Biochemical assesment of a nonthiol ACE inhibitor in active rheumatoid arthritis. J Rhe umatol 1990; 17: 603-608.

41. Beasley D, Eldridge M. Interleukin-1 $\beta$ and tumor necrosis factor-alfa synergistically induce NO synthase in rat vascular smooth muscle cells. Am J Physiol 1994; 266: R1197-R1203.

42. Manfield L, Jang D, Murrel GAC. Nitric oxide enhances cyclooxygenase activity in articular cartilage. Inflamm Res 1996; 45: 254-258.

\section{Received 20 September 1999; accepted 11 October 1999}




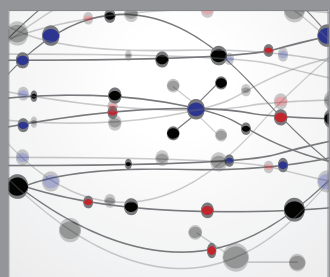

The Scientific World Journal
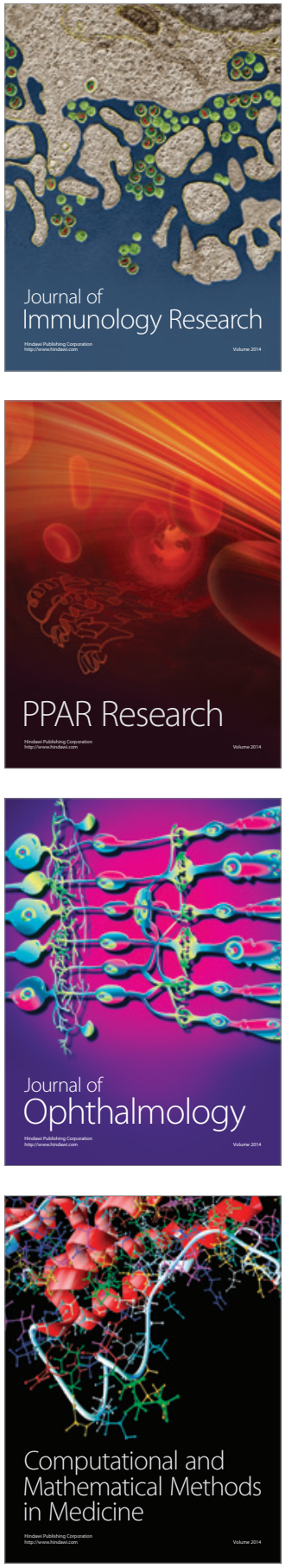

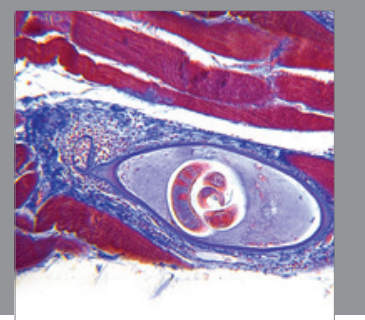

Gastroenterology

Research and Practice
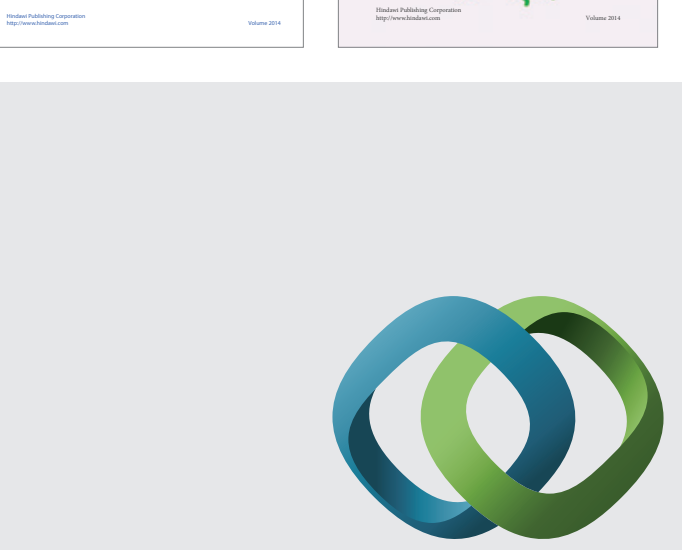

\section{Hindawi}

Submit your manuscripts at

http://www.hindawi.com
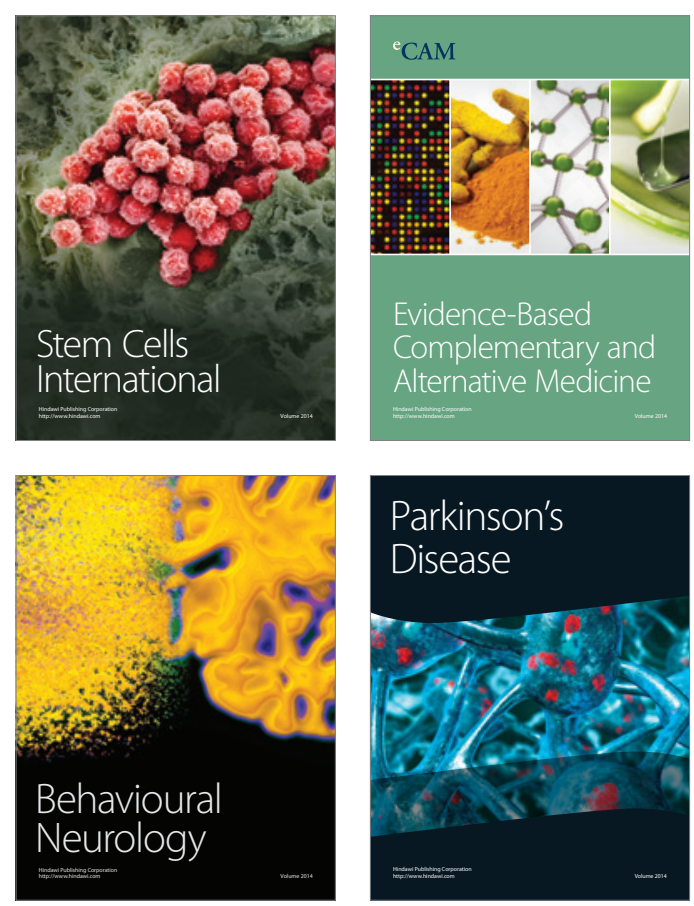

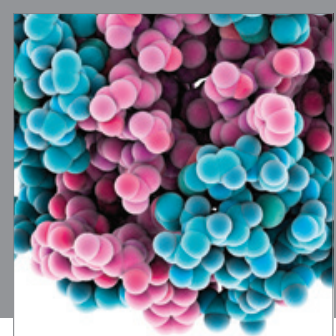

Journal of
Diabetes Research

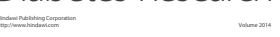

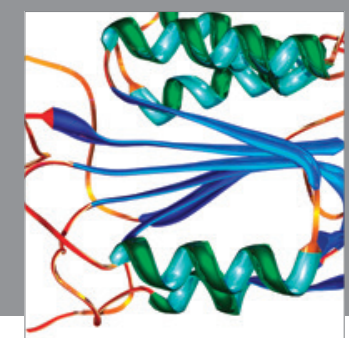

Disease Markers
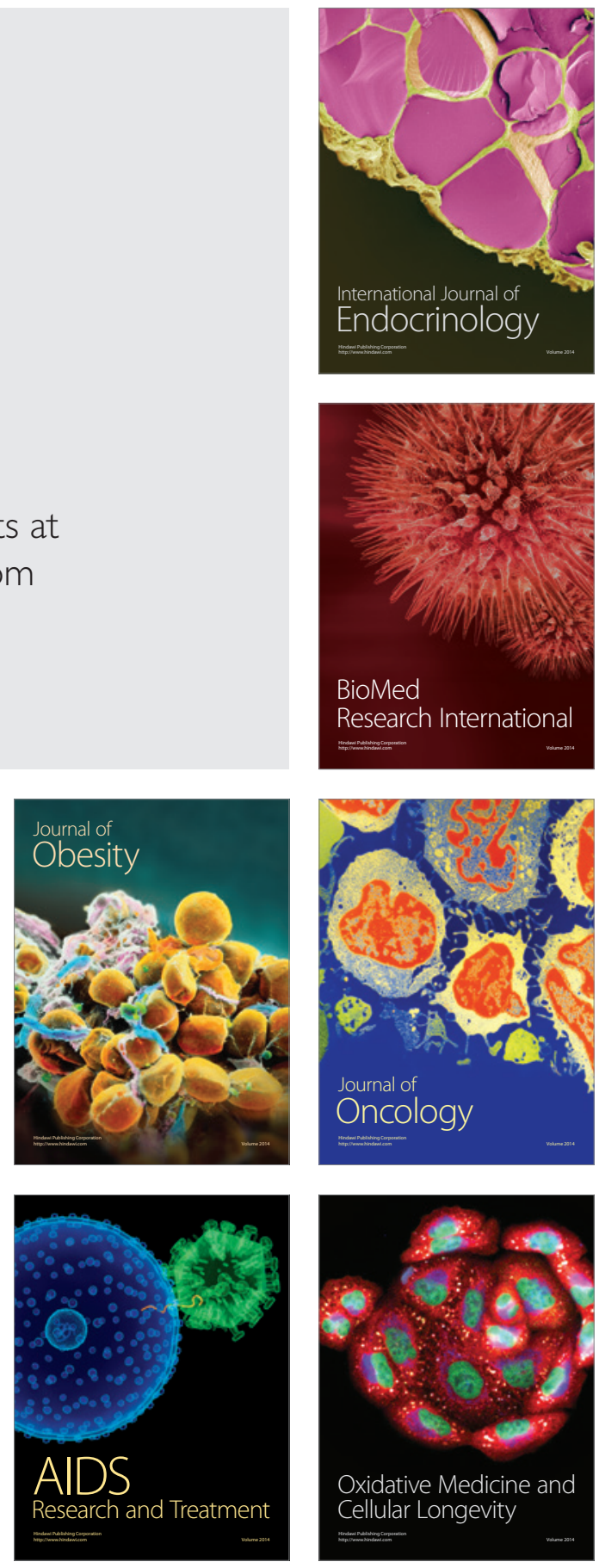